\title{
Expression of IncRNA MEG3 in asthma with different phenotypes and its relationship with course of disease
}

\author{
YAN FENG $^{1}$, CHANG YANG $^{2}$ and WEN YAN ${ }^{1}$ \\ ${ }^{1}$ Department of Pathology, Wuhan No. 1 Hospital, Wuhan, Hubei 430022; \\ ${ }^{2}$ Department of Respiratory Medicine, Hubei No.3 People's Hospital of Jianghan University, \\ Wuhan, Hubei 430030, P.R. China
}

Received September 5, 2019; Accepted November 1, 2019

DOI: $10.3892 /$ etm.2020.8414

\begin{abstract}
The purpose of this study was to explore the application value of lncRNA MEG3 in lung cancer. From March 2017 to March 2019, 119 asthma patients and 125 healthy people undergoing physical examination in the same period were selected as the research objects. The levels of IncRNA MEG3 in the peripheral blood of the two groups were compared, and the predictive value of $M E G 3$ for asthma as well as the differences in different inflammatory phenotypes were analyzed. The expression of $M E G 3$ was low in asthma patients $(\mathrm{P}<0.050)$, the diagnostic sensitivity and specificity for asthma were 79.83 and $66.40 \%$, respectively $(\mathrm{P}<0.001)$, it was the lowest in mixed granulocytic asthma $(\mathrm{P}<0.050)$ and was negatively correlated with the course of disease $(r=-0.666$, $\mathrm{P}<0.001)$. Logistic regression analysis showed that course of disease, inflammatory phenotype and $M E G 3$ were independent factors affecting recurrence of asthma $(\mathrm{P}<0.050) . M E G 3$ was low expressed in asthma and had good predictive value for it; in mixed granulocytic asthma, its expression was the lowest and the course of disease was closely related. It might be the key to the diagnosis and treatment of asthma in the future.
\end{abstract}

\section{Introduction}

Asthma, also known as bronchial asthma, refers to chronic airway inflammation involving a variety of cells and cell components. This inflammation often causes an increase in airway response, which can cause repeated attacks of wheezing, shortness of breath, chest distress, cough and other symptoms (1). Asthma is a very common chronic respiratory disease at present, with a high morbidity in all ages (2). According to statistics, the morbidity of asthma worldwide is

Correspondence to: Dr Chang Yang, Department of Respiratory Medicine, Hubei No.3 People's Hospital of Jianghan University, 26 Zhongshan Avenue, Wuhan, Hubei 430030, P.R. China

E-mail: yhh20q@163.com

Key words: IncRNA MEG3, asthma, course of disease, inflammatory phenotype, recurrence approximately 3.8/1,000 (3). Previous studies have confirmed that the pathogenic factors of asthma are complex, factors like heredity, inhalation allergen, air pollution and respiratory virus infection all may cause asthma (4). Asthma can cause respiratory failure, respiratory arrest, pneumothorax or mediastinal emphysema, and lung infection, and more serious cases will directly cause sudden death (5). Ebmeier et al (6) further indicated that the mortality caused by asthma was on the rise. At present, the diagnosis and treatment of asthma are complicated and difficult. In clinical practice, multiple comprehensive tests such as blood routine, sputum, lung function, blood gas, imaging technology and allergen are required to achieve the purpose of diagnosis, while treatment requires multi-functional treatment and extremely long treatment period, and the complete cure rate is relatively low $(7,8)$. Therefore, in order to effectively control the clinical harm of asthma, researchers are constantly working to explore and find new and effective diagnosis and treatment programs.

With the deepening of research, the application of longchain non-coding RNA (IncRNA) has gradually become a hot spot (9-11). As a tumor suppressor, lncRNA MEG3 has been proved to play a role in a number of tumor diseases $(12,13)$, and Devadoss et al (14) explained the importance of MEG3 in chronic obstructive pulmonary disease. However, there is no study that has yet confirmed the effect of MEG3 on asthma. Because chronic obstructive pulmonary disease was consistent with some pathogenic mechanisms of asthma, we speculated that $M E G 3$ also had special expression in asthma. In order to verify our conjecture, this experiment provided reference and guidance for future clinical diagnosis and treatment of asthma by exploring and analyzing the expression of $M E G 3$ in asthma patients and the situation of MEG3 in asthma with different inflammatory phenotypes.

\section{Materials and methods}

General information. A total of 119 asthma patients admitted to Wuhan No. 1 Hospital (Wuhan, China) from March 2017 to March 2019 and 125 healthy people undergoing physical examination at the same time were selected as the research objects for prospective analysis.

This experiment was approved by the Ethics Committee of Wuhan No. 1 Hospital. Patients who participated in this 
Table I. Primer sequence.

\begin{tabular}{lll}
\hline Genes & \multicolumn{1}{c}{ Upstream $\left(5^{\prime}-3^{\prime}\right)$} & \multicolumn{1}{c}{ Downstream (5'-3') } \\
\hline$M E G 3$ & TCGCTCTTCTCCATCGAACCG & GTAGGGCGACGACTTTGAGT \\
GAPDH & ATGGTGAAGGTCGGTGTGA & CCATGTAGTTGAGGTCAATGAG
\end{tabular}

research had complete clinical data. The signed informed consents were obtained from the patients or the guardians.

Inclusion and exclusion criteria. Inclusion criteria were as follows: Those in compliance with clinical manifestations of asthma; people who were diagnosed as asthma after a series of examinations in Wuhan No. 1 Hospital; those who had complete case data; those who agreed to cooperate and participate in the investigation of medical staff in Wuhan No. 1 Hospital; those who were 10-70 years old.

Exclusion criteria were as follows: Patients with other respiratory and lung diseases; patients with tumor; patients with autoimmune deficiency diseases; patients with systemic infection; patients with organ dysfunction; patients with other cardiovascular and cerebrovascular diseases; patients with drug allergy; patients with low treatment compliance for mental disorders; patients transferred to another hospital and patients with physical disabilities who could not take care of themselves.

Methods. Altogether $5 \mathrm{ml}$ of fasting venous blood from the two groups was drawn respectively into EDTA anticoagulants, left at room temperature for $30 \mathrm{~min}$ and centrifuged at $800 \mathrm{x} \mathrm{g}$ for $10 \mathrm{~min}$ to obtain upper serum, which was stored in a refrigerator at $-80^{\circ} \mathrm{C}$ for testing. PCR method was used to detect the expression of MEG3 in serum of patients. The collected serum was extracted with TRIzol kit (kit and corollary reagents were from Invitrogen; Thermo Fisher Scientific, Inc., Waltham, MA, USA) and the extracted total RNA was detected by ultraviolet spectrophotometer and agarose gel electrophoresis for purity, concentration and integrity of total RNA. TransScript ${ }^{\circledR}$ miRNA RT Enzyme Mix and 2X TS miRNA Reaction Mix were used to reverse transcription with total RNA, and the operation steps were strictly in accordance with the manufacturer's kit. Then PrimeScript RT Master Mix kit (kit and corollary reagents were from Takara Bio, Inc., Otsu, Japan) was used for PCR amplication experiment. PCR reaction system was as follows: cDNA $1 \mu \mathrm{l}$, upstream and downstream primers $0.4 \mu 1$ each (Table I), 2X TransTaq ${ }^{\circledR}$ Tip Green qPCR SuperMix $10 \mu$ l, Passive Reference Dye (50X) $0.4 \mu \mathrm{l}$, finally $\mathrm{ddH}_{2} \mathrm{O}$ supplemented to $20 \mu \mathrm{l}$. PCR reaction conditions were as follows: pre-denaturation at $94^{\circ} \mathrm{C}$ for $30 \mathrm{sec}$, denaturation at $94^{\circ} \mathrm{C}$ for $5 \mathrm{sec}$, annealing at $60^{\circ} \mathrm{C}$ for $30 \mathrm{sec}$, with a total of 40 cycles. Each sample was provided with 3 repeated wells, and the experiment was carried out 3 times. GAPDH was used as internal reference and $2^{-\Delta \mathrm{Cq}}$ was used for data analysis (14).

Observation indicators. Expression of MEG3 in two groups, the predictive value of $M E G 3$ for asthma, and expression of $M E G 3$ in asthma with different inflammatory phenotypes were observed. Patients in the research group were followed up for 3 months to record the recurrence of asthma and analyze the risk factors affecting it.

Statistical analysis. SPSS24.0 (IBM Corp., Armonk, NY, USA) was used to process and analyze all data, and GraphPad 8 was used to draw all graphical results. The counting data were expressed in the form of (rate), and Chi-square test was used for comparison between groups. The measurement data were expressed in the form of (mean \pm standard deviation), and the comparison between groups adopted t-test. One-way analysis of variance and LSD back testing were used for comparison among groups, and ROC curve was used to analyze the predicted value. Pearson's correlation coefficient was used for correlation analysis, and logistic regression analysis was used to analyze the risk factors. P-value $<0.050$ was considered statistically significant.

\section{Results}

Comparison of general information. Age, BMI, sex, smoking, living environment and nationality of the two groups were compared, there was no significant difference $(\mathrm{P}>0.050)$, while there was significant difference between the two groups in family medical history and history of respiratory disease $(\mathrm{P}<0.001)$ (Table II).

Comparison of the expression level of MEG3. The expression level of $M E G 3$ in the research group was significantly lower than that in the control group $(\mathrm{P}<0.001)$, and ROC curve analysis showed that when cut-off value was 4.295 , the predictive sensitivity, specificity, AUC and $95 \%$ CI for detection of MEG3 were $79.83 \%, 66.40 \%, 0.783$ and $0.725-0.840$, respectively $(\mathrm{P}<0.001)($ Fig. 1).

Expression of MEG3 in different inflammatory phenotypes. The expression level of MEG3 in patients with mixed granulocytic asthma was the lowest, followed by neutrophilic asthma and eosinophilic asthma, and the expression level of MEG3 in paucigranulocytic asthma was the highest $(\mathrm{P}<0.050)$ (Fig. 2).

Correlation analysis between MEG3 and course of disease. Pearson correlation coefficient analysis showed that the expression level of $M E G 3$ in the research group was negatively correlated with the course of disease $(\mathrm{r}=-0.666, \mathrm{P}<0.001)$ (Fig. 3).

Univariate analysis of factors affecting recurrence of asthma. A total of 119 patients in the research group were successfully followed up for 3 months, with a follow-up success rate of $100.0 \%$. Among them, 42 patients who had recurrence 
Table II. Comparison of general information of patients in the two groups [n (\%)].

\begin{tabular}{|c|c|c|c|c|}
\hline Characteristics & $\begin{array}{l}\text { Research group } \\
\quad(\mathrm{n}=119)\end{array}$ & $\begin{array}{l}\text { Control group } \\
(\mathrm{n}=125)\end{array}$ & t or $\chi^{2}$ value & P-value \\
\hline Age (years) & $31.5 \pm 16.4$ & $32.8 \pm 15.8$ & 0.631 & 0.529 \\
\hline Course of disease (years) & $2.42 \pm 0.78$ & & & \\
\hline $\mathrm{BMI}\left(\mathrm{kg} / \mathrm{cm}^{2}\right)$ & $22.81 \pm 2.18$ & $22.97 \pm 2.16$ & 0.576 & 0.565 \\
\hline Sex & & & 0.186 & 0.666 \\
\hline Male & $68(57.14)$ & $68(54.40)$ & & \\
\hline Female & $51(42.86)$ & $57(45.60)$ & & \\
\hline Smoking & & & 1.870 & 0.172 \\
\hline Yes & $75(63.03)$ & $68(54.40)$ & & \\
\hline No & $44(36.97)$ & $57(45.60)$ & & \\
\hline Living environment & & & 0.264 & 0.608 \\
\hline Cities and towns & $96(80.67)$ & $104(83.20)$ & & \\
\hline Countryside & $23(19.33)$ & $21(16.80)$ & & \\
\hline Family medical history & & & 22.240 & $<0.001$ \\
\hline Yes & $35(29.41)$ & $8(6.40)$ & & \\
\hline No & $84(70.59)$ & $117(93.60)$ & & \\
\hline History of respiratory disease & & & 13.350 & $<0.001$ \\
\hline Yes & $24(20.17)$ & $6(4.80)$ & & \\
\hline No & $95(79.83)$ & $119(95.20)$ & & \\
\hline Nationality & & & 0.462 & 0.497 \\
\hline Han & $112(94.12)$ & $120(96.00)$ & & \\
\hline Ethnic minorities & $7(5.88)$ & $5(4.00)$ & & \\
\hline Working and learning environment & & & 0.422 & 0.516 \\
\hline Outdoor & $79(66.39)$ & $78(62.40)$ & & \\
\hline Indoor & $40(33.61)$ & $47(37.60)$ & & \\
\hline \multicolumn{5}{|l|}{ Inflammatory phenotype } \\
\hline Eosinophilic asthma & $49(41.18)$ & & & \\
\hline Neutrophilic asthma & $32(26.89)$ & & & \\
\hline Mixed granulocytic asthma & $26(21.85)$ & & & \\
\hline Paucigranulocytic asthma & $12(10.08)$ & & & \\
\hline
\end{tabular}

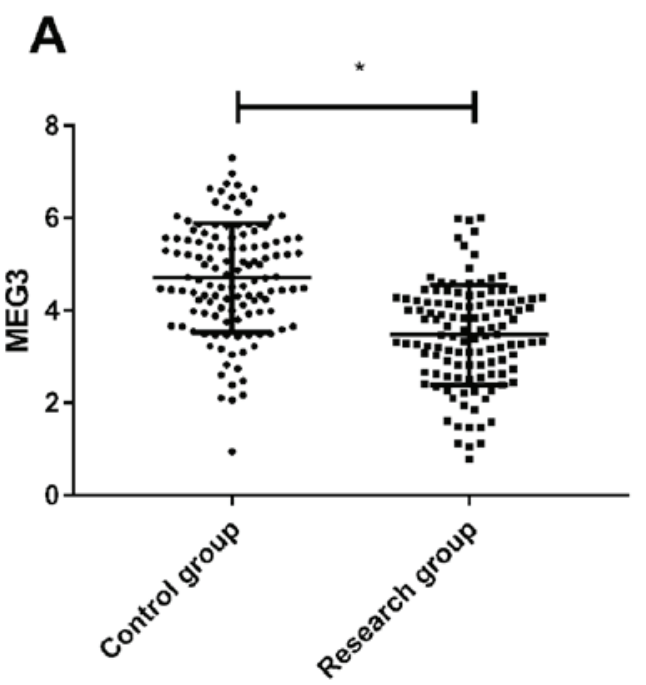

B

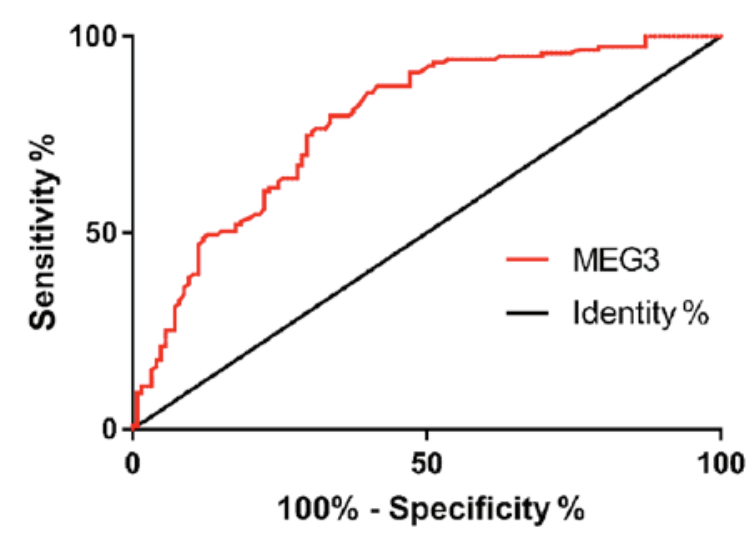

Figure 1. Analysis of the expression level of MEG3 and its diagnostic value. (A) Compared with the expression level of MEG3 in serum of the two groups, the research group was lower than the control group ( $(\mathrm{P}<0.050)$. (B) ROC curve analysis of MEG3 in predicting asthma. 
Table III. Univariate analysis

\begin{tabular}{|c|c|c|c|c|}
\hline Characteristics & $\begin{array}{l}\text { Recurrence group } \\
\qquad(\mathrm{n}=42)\end{array}$ & $\begin{array}{l}\text { Non-recurrence group } \\
\qquad(\mathrm{n}=77)\end{array}$ & $\chi^{2}$ value & P-value \\
\hline Age & & & 0.483 & 0.487 \\
\hline$\leq 31.5$ & $24(57.14)$ & $49(63.64)$ & & \\
\hline$>31.5$ & $18(42.86)$ & $28(36.36)$ & & \\
\hline Course of disease (years) & & & 11.180 & $<0.001$ \\
\hline$\leq 2.42$ & $15(35.71)$ & $52(67.53)$ & & \\
\hline$>2.42$ & $27(64.29)$ & $25(32.47)$ & & \\
\hline BMI $\left(\mathrm{kg} / \mathrm{cm}^{2}\right)$ & & & 0.150 & 0.698 \\
\hline$\leq 22.81$ & $23(54.76)$ & $45(58.44)$ & & \\
\hline$>22.81$ & $19(45.24)$ & $32(41.56)$ & & \\
\hline Sex & & & 0.150 & 0.698 \\
\hline Male & $23(54.76)$ & 45 (58.44) & & \\
\hline Female & $19(45.24)$ & $32(41.56)$ & & \\
\hline Smoking & & & 14.340 & $<0.001$ \\
\hline Yes & $36(85.71)$ & $39(50.65)$ & & \\
\hline No & $6(14.29)$ & $38(49.35)$ & & \\
\hline Living environment & & & 0.184 & 0.668 \\
\hline Cities and towns & $33(78.57)$ & $63(81.82)$ & & \\
\hline Countryside & $9(21.43)$ & $14(18.18)$ & & \\
\hline Family medical history & & & 0.074 & 0.785 \\
\hline Yes & $13(30.95)$ & $22(28.57)$ & & \\
\hline No & $29(69.05)$ & $55(71.43)$ & & \\
\hline History of respiratory disease & & & 30.380 & $<0.001$ \\
\hline Yes & $20(47.62)$ & $4(5.19)$ & & \\
\hline No & $22(52.38)$ & $73(94.81)$ & & \\
\hline Nationality & & & 0.147 & 0.701 \\
\hline Han & $40(95.24)$ & $72(93.51)$ & & \\
\hline Ethnic minorities & $2(4.76)$ & $5(6.49)$ & & \\
\hline Working (learning) environment & & & 6.171 & 0.013 \\
\hline Outdoor & $34(80.95)$ & $45(58.44)$ & & \\
\hline Indoor & $8(19.05)$ & $32(41.56)$ & & \\
\hline Inflammatory phenotype & & & 9.698 & 0.021 \\
\hline Eosinophilic asthma & $16(38.10)$ & $33(42.86)$ & & \\
\hline Neutrophilic asthma & $10(23.81)$ & $22(28.57)$ & & \\
\hline Mixed granulocytic asthma & $16(38.10)$ & $10(12.99)$ & & \\
\hline Paucigranulocytic asthma & $2(4.76)$ & $10(12.99)$ & & \\
\hline MEG3 & & & 22.800 & $<0.001$ \\
\hline$\leq 3.48$ & $35(83.33)$ & $29(37.66)$ & & \\
\hline$>3.48$ & $7(16.67)$ & $48(62.34)$ & & \\
\hline
\end{tabular}

of asthma were regarded as recurrence group and the other 77 patients who did not recur were treated as non-recurrence group. Univariate analysis showed that age, BMI, sex, family medical history and nationality were not the single factors affecting recurrence of asthma $(\mathrm{P}>0.050)$, while course of disease, smoking, living environment, history of respiratory, working (learning) environment, inflammatory phenotype and $M E G 3$ were the single factors affecting recurrence of asthma $(\mathrm{P}<0.050)$ (Table III).
Multivariate analysis of factors affecting recurrence of asthma. The indicators with differences in univariate analysis were included in the assignment (Table IV), and the results were input into SPSS and then selected to go forward: LR was used for logistic regression analysis, and the results revealed that the living environment, history of respiratory disease and working (learning) environment were not independent factors influencing recurrence of asthma $(\mathrm{P}>0.050)$, while the course of disease and inflammatory phenotype were independent 
Table IV. Assignment table.

Factors Assignment

Course of disease

Smoking

Living environment

History of respiratory disease

Working (learning) environment Inflammatory phenotype

MEG3

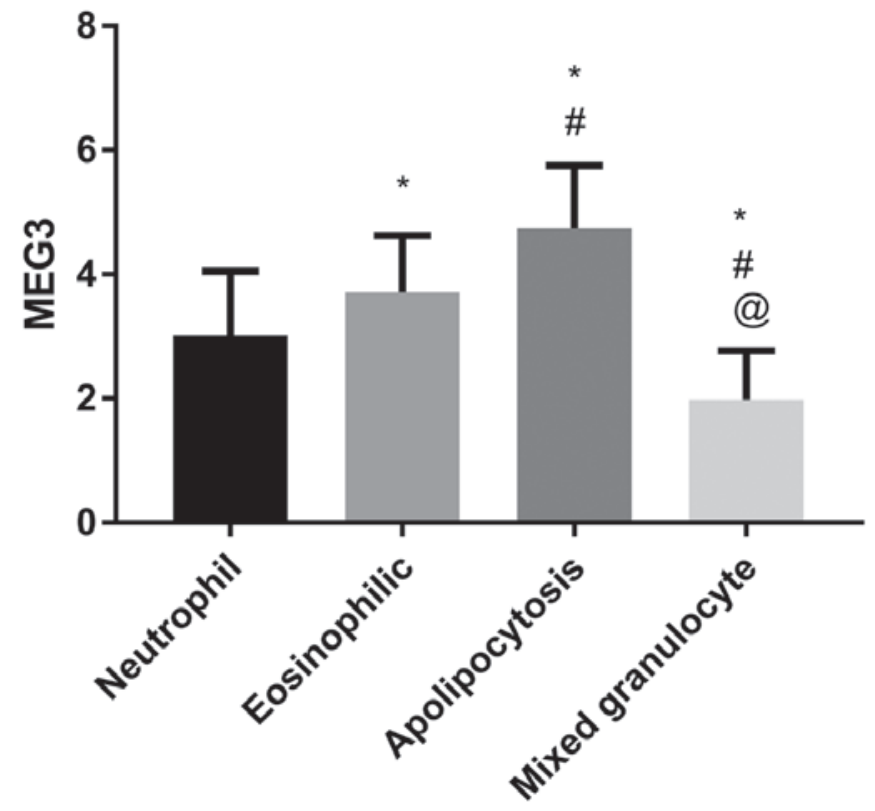

Figure 2. Expression of MEG3 in different inflammatory phenotypes ${ }^{*} \mathrm{P}<0.050$, comparison with eosinophilic asthma; ${ }^{\#} \mathrm{P}<0.050$, comparison with neutrophilic asthma; ${ }^{\circledR} \mathrm{P}<0.050$, comparison with mixed granulocytic asthma.

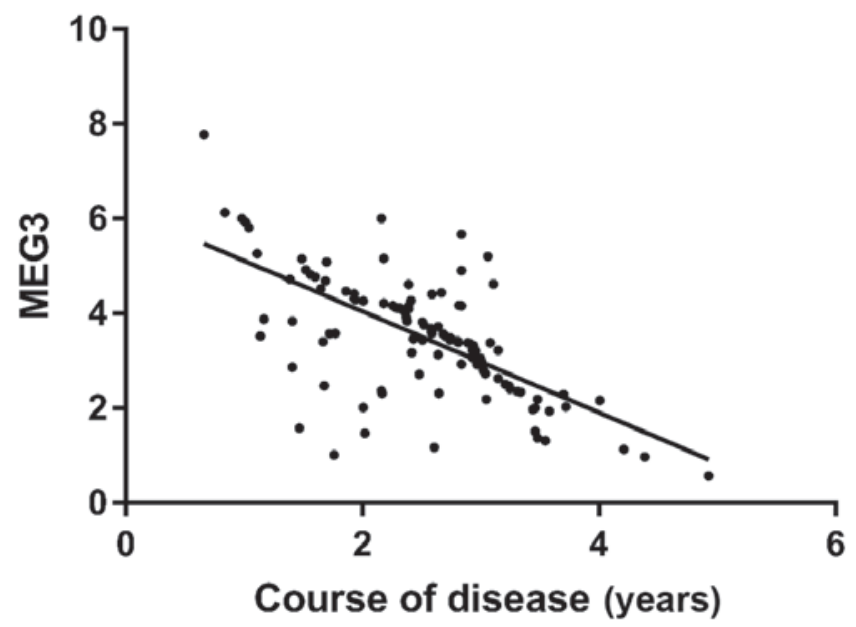

Figure 3. Correlation analysis between MEG3 and course of disease in the research group. risk factors influencing recurrence of asthma $(\mathrm{P}<0.050)$, and $M E G 3$ was independent protective factor influencing recurrence of asthma $(\mathrm{P}<0.050)($ Table $\mathrm{V})$.

\section{Discussion}

Asthma is airway inflammation involving T lymphocytes, mast cells and other inflammatory mediator cells, which is mainly manifested by symptoms such as wheezing, cough and dyspnea (15). Asthma is a respiratory disease caused by the combination of internal and external environment of the body (16). The degree of air turbidity and inhaled particles in the external environment are the keys to asthma (17), while lncRNA may play a crucial role in the internal environment of the body. IncRNA is a kind of RNA molecule with transcripts over 200nt in length and no protein coding, and it can exert its biological function through a variety of mechanisms (18). $M E G 3$ has been proved to normally play an anti-cancer role in tumor diseases (19), but its role in asthma is not yet clear. Facing the increasingly serious asthma diseases, it is of great significance for us to study the situation of MEG3 in asthma for its clinical diagnosis and treatment in the future.

The results of this experiment showed that $M E G 3$ was low expressed in asthma patients, suggesting that MEG3 might be involved in the occurrence of asthma. Zhou et al (20) also stated that $M E G 3$ was also low expressed in bronchial epithelial cells, which could support our experimental results. Therefore, we speculated that the role of $M E G 3$ in asthma might be similar to that of tumor suppressor genes. Some studies claimed that $M E G 3$ inhibited cell growth, reduced protein synthesis of cells, and down-regulated apoptosis-related protein Bcl-xl to accelerate apoptosis through $\mathrm{P} 13 \mathrm{~K} / \mathrm{m}$-TOR signaling pathway (21). However, Wang et al (22) indicated that FIZZ1 was the key to cause asthma through airway P13K/Akt signaling, and Zhang et al (23) studied that P13K and Notch signaling pathway were the keys to regulate activation and proliferation of $\mathrm{T}$ lymphocytes in asthma patients. Zhang et al (24) confirmed that the onset of asthma required activation of the m-TOR signaling pathway. Based on the above, we suspected that the role of $M E G 3$ in asthma might also be carried out through $\mathrm{P} 13 \mathrm{~K} / \mathrm{m}-\mathrm{TOR}$ signaling pathway. However, due to the failure to carry out basic experiments, we still could not verify our hypothesis, and this would also be a focus of our future research for further analysis. Furthermore, we analyzed the predictive value of $M E G 3$ for asthma, and the results showed that when cut-off value was 4.295 , the predictive sensitivity and specificity of MEG3 for asthma were 79.83 and $66.40 \%$, respectively. It indicated that $M E G 3$ could be used as an auxiliary diagnostic indicator for asthma in the future and could be used for early screening clinically. Compared with the traditional detection of asthma (such as sputum smear, imaging and analysis of blood gas) (25), the advantage of detecting $M E G 3$ in serum lies in the convenient acquisition of detection samples. Peripheral blood, as the most convenient and minimally invasive detection sample in clinical detection, has a longer preservation period and is conducive to clinical follow-up at any time. However, results of serum test are more objective than imaging results and do not need to rely on the subjective judgment of clinicians for prediction, which also reduces misdiagnosis and missed diagnosis caused by human factors to a 
Table V. Results of multivariate analysis.

\begin{tabular}{lccccrc}
\hline Factors & B & S.E. & Wald & P-value & Exp (B) & 95\% CI \\
\hline Course of disease & 2.543 & 0.043 & 12.542 & 0.012 & 12.621 & $12.162-13.425$ \\
Smoking & 0.007 & 0.785 & 1.242 & 0.214 & 1.241 & $-0.624-2.572$ \\
Living environment & 0.004 & 0.852 & 1.026 & 0.128 & 1.007 & $-0.715-2.624$ \\
History of respiratory disease & 0.248 & 0.242 & 4.162 & 0.274 & 1.624 & $1.124-2.128$ \\
Working (learning) environment & 1.358 & 0.776 & 5.242 & 0.324 & 3.242 & $1.135-2.165$ \\
Inflammatory phenotype & 3.684 & 0.097 & 14.684 & 0.011 & 35.242 & $34.162-35.985$ \\
MEG3 & 1.492 & 0.687 & 4.732 & 0.030 & 7.862 & $1.157-16.527$ \\
\hline
\end{tabular}

certain extent. However, by comparing the expression level of $M E G 3$ in asthma with different inflammatory phenotypes, it could be seen that the expression level of $M E G 3$ was the lowest in patients with mixed granulocytic asthma and the highest in patients with paucigranulocytic asthma, which was basically consistent with the pathological condition of eliminating inflammatory phenotypes (26). Mixed granulocytic asthma is the most serious type of asthma, which is characterized by recurrent attacks and refractory treatment, while paucigranulocytic asthma is a well-controlled or intermittent dyspnea. Such patients usually have a short course of disease and a mild condition, and can basically recover after treatment (27). The differences in expression of $M E G 3$ in asthma with different phenotypes also indicated that $M E G 3$ might be closely related to the development of the disease, and the further analysis of the relationship between $M E G 3$ and the course of disease in the research group also proved the same. This also suggested that monitoring of $M E G 3$ in asthma patients could be used to judge the course of illness or rehabilitation of patients in the future. However, through logistic regression analysis, we found that the course of disease and inflammatory phenotype were independent risk factors for recurrence of asthma, and $M E G 3$ was an independent protective factor for recurrence of asthma. As the pathological process of asthma, the course of disease and inflammatory phenotype had been recognized unanimously in clinical practice, and the effect of $M E G 3$ on recurrence of asthma indicated that MEG3 might be a potential indicator for future treatment of asthma and had extremely high clinical application prospect.

The results of this experiment revealed that $M E G 3$ was low expressed in asthma patients, while Chen et al (28) discovered MEG3 was highly expressed in hepatocytes. The reason for the differences with our results also showed that $M E G 3$ played different biological effects in different diseases. However, since we have not been able to determine the exact mechanism of action of $M E G 3$ on asthma through basic experiments, this is the limitation to our research. However, due to the short experimental period, it is impossible to judge the impact of $M E G 3$ on the long-term prognosis of asthma patients. In the future, we will expand the research period and sample size to obtain more detailed and representative experimental results.

In conclusion, $M E G 3$ is low expressed in asthma and has good predictive value for it, while its expression is the lowest and course of disease is closely related in mixed granulocytic asthma, which may be the key to the diagnosis and treatment of asthma in the future.

\section{Acknowledgements}

Not applicable.

\section{Funding}

No funding was received.

\section{Availability of data and materials}

The datasets used and/or analyzed during the present study are available from the corresponding author on reasonable request.

\section{Authors' contributions}

YF wrote the manuscript, interpreted and analyzed the patient data. CY and WY designed the study and performed the experiment. WY was responsible for the analysis and discussion of the data. All authors read and approved the final manuscript.

\section{Ethics approval and consent to participate}

The study was approved by the Ethics Committee of Wuhan No. 1 Hospital (Wuhan, China). Patients who participated in this research had complete clinical data. The signed informed consents were obtained from the patients or the guardians.

\section{Patient consent for publication}

Not applicable.

\section{Competing interests}

The authors declare that they have no competing interests.

\section{References}

1. Pavord ID, Beasley R, Agusti A, Anderson GP, Bel E, Brusselle G, Cullinan P, Custovic A, Ducharme FM, Fahy JV, et al: After asthma: Redefining airways diseases. Lancet 391: 350-400, 2018.

2. Nunes C, Pereira AM and Morais-Almeida M: Asthma costs and social impact. Asthma Res Pract 3: 1, 2017. 
3. Winer RA, Qin X, Harrington T, Moorman J and Zahran $\mathrm{H}$ Asthma incidence among children and adults: Findings from the Behavioral Risk Factor Surveillance system asthma call-back survey - United States, 2006-2008. J Asthma 49: 16-22, 2012.

4. Loftus PA and Wise SK: Epidemiology of asthma. Curr Opin Otolaryngol Head Neck Surg 24: 245-249, 2016.

5. D'Amato G, Vitale C, Molino A, Stanziola A, Sanduzzi A, Vatrella A, Mormile M, Lanza M, Calabrese G, Antonicelli L, et al: Asthma-related deaths. Multidiscip Respir Med 11: 37, 2016.

6. Ebmeier S, Thayabaran D, Braithwaite I, Bénamara C, Weatherall $\mathrm{M}$ and Beasley R: Trends in international asthma mortality: Analysis of data from the WHO Mortality Database from 46 countries (1993-2012). Lancet 390: 935-945, 2017.

7. Horak F, Doberer D, Eber E, Horak E, Pohl W, Riedler J, Szépfalusi Z, Wantke F, Zacharasiewicz A and Studnicka M: Diagnosis and management of asthma - Statement on the 2015 GINA Guidelines. Wien Klin Wochenschr 128: 541-554, 2016.

8. Ichinose $M$, Sugiura $H$, Nagase $H$, Yamaguchi $M$, Inoue $H$, Sagara H, Tamaoki J, Tohda Y, Munakata M; Japanese Society of Allergology: Japanese guidelines for adult asthma 2017. Allergol Int 66: 163-189, 2017

9. Paralkar VR, Taborda CC, Huang P, Yao Y, Kossenkov AV, Prasad R, Luan J, Davies JO, Hughes JR, Hardison RC, et al: Unlinking an lncRNA from its associated cis element. Mol Cell 62: 104-110,2016.

10. Nie W, Ge HJ, Yang XQ, Sun X, Huang H, Tao X, Chen WS and Li B: LncRNA-UCA1 exerts oncogenic functions in non-smal cell lung cancer by targeting miR-193a-3p. Cancer Lett 371: 99-106, 2016

11. Li W, Zhai L, Wang H, Liu C, Zhang J, Chen W and Wei Q: Downregulation of LncRNA GAS5 causes trastuzumab resistance in breast cancer. Oncotarget 7: 27778-27786, 2016

12. Boon RA, Hofmann P, Michalik KM, Lozano-Vidal N, Berghäuser D, Fischer A, Knau A, Jaé N, Schürmann C and Dimmeler S: Long noncoding RNA Meg3 controls endothelial cell aging and function: Implications for regenerative angiogenesis. J Am Coll Cardiol 68: 2589-2591, 2016.

13. Zhang J, Yao T, Wang Y, Yu J, Liu Y and Lin Z: Long noncoding RNA MEG3 is downregulated in cervical cancer and affects cell proliferation and apoptosis by regulating miR-21. Cancer Biol Ther 17: 104-113, 2016.

14. Devadoss D, Long C, Langley RJ, Manevski M, Nair M, Campos MA, Borchert G, Rahman I and Chand HS: Long noncoding transcriptome in chronic obstructive pulmonary disease. Am J Respir Cell Mol Biol: Sep 5, 2019 (Epub ahead of print).

15. Borish L: The immunology of asthma: Asthma phenotypes and their implications for personalized treatment. Ann Allergy Asthma Immunol 117: 108-114, 2016.

16. Yang IV, Lozupone CA and Schwartz DA: The environment, epigenome, and asthma. J Allergy Clin Immunol 140: 14-23, 2017.
17. Burbank AJ, Sood AK, Kesic MJ, Peden DB and Hernandez ML: Environmental determinants of allergy and asthma in early life. J Allergy Clin Immunol 140: 1-12, 2017.

18. Quinn JJ, Zhang QC, Georgiev P, Ilik IA, Akhtar A and Chang HY: Rapid evolutionary turnover underlies conserved lncRNA-genome interactions. Genes Dev 30: 191-207, 2016.

19. Chak WP, Lung RW, Tong JH, Chan SY, Lun SW, Tsao SW, Lo KW and To KF: Downregulation of long non-coding RNA MEG3 in nasopharyngeal carcinoma. Mol Carcinog 56: 1041-1054, 2017.

20. Zhou C, Huang C, Wang J, Huang H, Li J, Xie Q, Liu Y, Zhu J, Li Y, Zhang D, et al: LncRNA MEG3 downregulation mediated by DNMT3b contributes to nickel malignant transformation of human bronchial epithelial cells via modulating PHLPP1 transcription and HIF-1 $\alpha$ translation. Oncogene 36: 3878-3889, 2017.

21. Xu DH, Chi GN, Zhao CH and Li DY: Long noncoding RNA MEG3 inhibits proliferation and migration but induces autophagy by regulation of Sirt7 and PI3K/AKT/mTOR pathway in glioma cells. J Cell Biochem 120: 7516-7526, 2018.

22. Wang J, Li F, Yang M, Wu J, Zhao J, Gong W, Liu W, Bi W and Dong L: FIZZ1 promotes airway remodeling through the PI3K/ Akt signaling pathway in asthma. Exp Ther Med 7: 1265-1270, 2014.

23. Zhang W, Nie Y, Chong L, Cai X, Zhang H, Lin B, Liang Y and $\mathrm{Li}$ C: PI3K and Notch signal pathways coordinately regulate the activation and proliferation of T lymphocytes in asthma. Life Sci 92: 890-895, 2013.

24. Zhang Y, Jing Y, Qiao J, Luan B, Wang X, Wang L and Song Z: Activation of the mTOR signaling pathway is required for asthma onset. Sci Rep 7: 4532, 2017.

25. Bos LD, Sterk PJ and Fowler SJ: Breathomics in the setting of asthma and chronic obstructive pulmonary disease. J Allergy Clin Immunol 138: 970-976, 2016.

26. Chung S, Lee TJ, Reader BF, Kim JY, Lee YG, Park GY, Karpurapu M, Ballinger MN, Qian F, Rusu L, et al: FoxO1 regulates allergic asthmatic inflammation through regulating polarization of the macrophage inflammatory phenotype. Oncotarget 7: 17532-17546, 2016.

27. Taylor SL, Leong LEX, Choo JM, Wesselingh S, Yang IA, Upham JW, Reynolds PN, Hodge S, James AL, Jenkins C, et al: Inflammatory phenotypes in patients with severe asthma are associated with distinct airway microbiology. J Allergy Clin Immunol 141: 94-103.e15, 2018.

28. Chen DL, Shen DY, Han CK and Tian Y: LncRNA MEG3 aggravates palmitate-induced insulin resistance by regulating miR-185-5p/Egr2 axis in hepatic cells. Eur Rev Med Pharmacol Sci 23: 5456-5467, 2019.

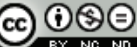

This work is licensed under a Creative Commons Attribution-NonCommercial-NoDerivatives 4.0 International (CC BY-NC-ND 4.0) License. 